\title{
Three-year outcome of local injection of autologous stromal vascular fraction cells and microfat in refractory perianal fistulas of Crohn's disease
}

\author{
Lucas Guillo ${ }^{1,2^{*}+}$ (1), Fanny Grimaud ${ }^{2 \dagger}$, Fanny Houser ${ }^{1}$, Caroline Prost ${ }^{3}$, Elisabeth Jouve ${ }^{4}$, Cécile Philandrianos ${ }^{5}$, \\ Maxime Abellan ${ }^{5}$, Julie Veran ${ }^{2}$, Carine Visee ${ }^{6}$, Laura Beyer-Berjot ${ }^{6}$, Ariadne Desjeux ${ }^{1}$, Françoise Dignat-George ${ }^{7}$, \\ Marc Leone ${ }^{8}$, Jean-Charles Grimaud ${ }^{1,9}$, Florence Sabatier ${ }^{2,7}$, Mélanie Serrero ${ }^{1}$ and Jérémy Magalon ${ }^{2,7}$
}

\begin{abstract}
Perianal fistulas in Crohn's disease are frequent and disabling, with a major impact on patients' quality of life. Cellbased therapy using mesenchymal stem cells represents new hope for these patients, but long-term efficacy remains challenging. In a pilot study, including patients with refractory complex perianal fistulas, autologous adipose-derived stromal vascular fraction (ADSVF) combined with microfat achieved combined remission in $60 \%$ of cases, with a good safety profile at 1 year. The purpose of this study is to assess whether these results were maintained at longer term. The safety and efficacy data of the ten patients were evaluated retrospectively 3 years after injection on the basis of clinical and radiological data. MRI were analysed according to the MAGNIFI-CD score. No adverse event was attributed to the experimental stem-cell treatment. Combined remission was achieved in 7 patients (70\%) and associated with a significant improvement in the MAGNIFI-CD MRI score. In conclusion, the safety and efficacy of ADSVF and microfat injection in Crohn's disease fistulas were maintained at 3 years, demonstrating that this innovative strategy is effective in producing a long-lasting healing effect. The ongoing multicentre randomized placebo-controlled trial (NCT04010526) will be helpful to define the place for this approach in the current therapeutic arsenal.
\end{abstract}

Keywords: Stromal vascular fraction, Crohn's disease, Perianal fistulas, Long-term outcome

\section{Introduction}

Perianal fistulas in Crohn's disease are frequent and disabling, with a major impact on patients' quality of life [1]. Despite optimal treatment, combining biologics and surgical intervention, only 35 to $50 \%$ of patients with complex fistulas achieve long-term remission $[2,3]$. To

*Correspondence: lucas.guillo690@gmail.com

†Lucas Guillo and Fanny Grimaud have contributed equally to this work ${ }^{1}$ Gastroenterology Department, Assistance Publique Hôpitaux de

Marseille, University Hospital of Marseille Nord (AP-HM), Chemin des Bourrely, 13015 Marseille, France

Full list of author information is available at the end of the article address higher remission rate, new strategies are developed, including stem cell therapy. Panes and colleagues evaluated allogeneic mesenchymal stem cells (MSCs) derived from adipose tissue $[4,5]$ and obtained a 1-year combined remission of $56 \%$ (vs $40 \%$ in the control group). However, long-term efficacy remains challenging.

Autologous adipose-derived stromal vascular fraction (ADSVF) represents an alternative to ex vivo-cultured MSCs and can be easily obtained within few hours after lipoaspiration. ADSVF corresponds to the cell pellet obtained after enzymatic digestion and removal of adipocytes. This heterogeneous mixture of cells contains not only MSCs, but also immune cells and endothelial original author(s) and the source, provide a link to the Creative Commons licence, and indicate if changes were made. The images or other third party material in this article are included in the article's Creative Commons licence, unless indicated otherwise in a credit line to the material. If material is not included in the article's Creative Commons licence and your intended use is not permitted by statutory regulation or exceeds the permitted use, you will need to obtain permission directly from the copyright holder. To view a copy of this licence, visit http://creativecommons.org/licenses/by/4.0/. The Creative Commons Public Domain Dedication waiver (http://creativeco mmons.org/publicdomain/zero/1.0/) applies to the data made available in this article, unless otherwise stated in a credit line to the data. 
cell progenitors that synergistically provide pro-angiogenic, regenerative and immunomodulatory activities [6, 7]. We obtained encouraging results in the ADICROHN pilot study, using local injection of ADSVF associated with microfat: combined remission (defined as the complete cessation of fistula suppuration, with no collection greater than $2 \mathrm{~cm}$ on magnetic resonance imaging (MRI)) in six of ten patients $(60 \%)$ at week 48 , with significant improvement in quality of life and a good safety profile [8]. We aimed to assess whether the safety and efficacy obtained 1 year after the local injection of ADSVF and microfat on Crohn's complex and refractory perianal fistulas could be maintained 3 years after.

\section{Methods}

The ten patients treated in the ADICROHN trial [8] were evaluated at 3 years using clinical examination, the Perianal Crohn's Disease Activity Index (PDAI), the Short Inflammatory Bowel Disease Questionnaire (SIBDQ) and MRI. Safety data were retrospectively collected using the computerized patient record. Eligible patients to the ADICROHN prospective pilot study (NCT 02520843) presented Crohn's disease with low luminal activity (Crohn Disease Activity Index $<250$ ) complicated by one or more complex perianal fistulas refractory to surgical drainage with setons and anti-TNF alpha treatment. Patients were excluded if they had a collection of more than $2 \mathrm{~cm}$, active proctitis, anorectal stenosis, or surgical treatment other than surgical drainage or seton placement.

The cell therapy procedure required one surgical procedure for fat harvesting and another surgical procedure for microfat and ADSVF injection. The fat was harvesting was previously described [9]. ADSVF was obtained within $4 \mathrm{~h}$ of lipoaspiration by an automated process (Celution800/CRS system, Cytori Therapeutics, San Diego, USA). Then, ADSVF was aseptically recovered and suspended in $5 \mathrm{~mL}$ Lactate Ringer's solution. The final cell suspension was transferred into a syringe $(10 \mathrm{~mL})$ for injection. The treatment administration was also previously reported [8]. A median of $22.8 \times 10^{6}$ $\left[10.9-47.8 \times 10^{6}\right]$ viable nucleated cells was injected, and the median quantity of microfat injected was $10.8 \mathrm{~mL}$ [5-17 mL].

Categorical variables were described as percentage, while continuous variables were reported as mean and standard deviation.

\section{Results}

The characteristics and treatments of patients at baseline are available in Table 1 . No serious adverse event was reported related to the fat harvesting procedure. Moderate pain at the lipoaspiration site that resolved in less
Table 1 Patients and disease characteristics at baseline

\begin{tabular}{|c|c|}
\hline Characteristics at baseline & $n=10$ \\
\hline Men & $6(60 \%)$ \\
\hline Age (year) & $37.3 \pm 12.8$ \\
\hline \multicolumn{2}{|l|}{ Smoking status } \\
\hline Active smoker & $3(30 \%)$ \\
\hline Non-smoker & $3(30 \%)$ \\
\hline Former smoker & $4(40 \%)$ \\
\hline $\mathrm{BMI}^{+}$ & $24.4 \pm 5$ \\
\hline$C D^{\ddagger}$ duration (year) & $11.8 \pm 11.4$ \\
\hline $\mathrm{CDAl}^{\S}$ score & $139 \pm 116$ \\
\hline $\mathrm{SIBDQ}^{\dagger+}$ score & $43 \pm 12$ \\
\hline Fistula duration (year) & $5.2 \pm 4.9$ \\
\hline $\mathrm{PDA}^{f^{\ddagger \ddagger}}$ score & $7.3 \pm 2.7$ \\
\hline \multicolumn{2}{|l|}{ Number of fistula tract } \\
\hline 1 & $4(40 \%)$ \\
\hline 2 & $5(50 \%)$ \\
\hline$>2$ & $1(10 \%)$ \\
\hline \multicolumn{2}{|l|}{ Type of fistula } \\
\hline Intersphincteric & $1(10 \%)$ \\
\hline Trans-sphincteric & $8(80 \%)$ \\
\hline Suprasphincteric & $0(0 \%)$ \\
\hline Extrasphincteric & $1(10 \%)$ \\
\hline History of fistula surgery & $10(100 \%)$ \\
\hline \multicolumn{2}{|l|}{ Prior fistula treatment failure } \\
\hline At least 1 anti-TNFa ${ }^{\S \S}\left( \pm I S^{+\dagger+}\right)$ & $10(100 \%)$ \\
\hline 2 anti-TNFa & $8(80 \%)$ \\
\hline Vedolizumab & $3(30 \%)$ \\
\hline Derivation ileostomy & $2(20 \%)$ \\
\hline \multicolumn{2}{|l|}{ Baseline treatment } \\
\hline Anti-TNFa & $7(70 \%)$ \\
\hline Vedolizumab & $3(30 \%)$ \\
\hline
\end{tabular}

Data represent frequency $\mathrm{n}(\%)$ or mean and standard deviation

${ }^{\dagger}$ Body Mass Index

₹ Crohn's Disease

$\S$ Crohn's Disease Activity Index

${ }^{\text {tt }}$ Short Inflammatory Bowel Disease Questionnaire

\#‡ Perianal Crohn's Disease Activity Index

$\$$ Anti-Tumour Necrosis Factor alpha

${ }^{++t}$ Immunosuppressant

than one week under simple oral analgesia was observed in 4 patients (40\%), and one cutaneous reaction secondary to anesthetics was also noticed. The adverse and intercurrent events between the first and the third years of follow-up were recorded and are listed in Table 2. A new fistula tract, in a site other than the treated fistula, appeared in one patient and was treated with fistulotomy. Perianal abscesses occurred in three patients and necessitated draining with setons, and two of them were treated punctually with a combination of antibiotics. Two 
Table 2 Adverse and intercurrent events at 3 years

\begin{tabular}{ll}
\hline Events & $\boldsymbol{n}(\%)$ \\
\hline Perianal pain & $4(40 \%)$ \\
Local inflammation & $4(40 \%)$ \\
New fistula tract & $1(10 \%)$ \\
Abscess & $3(30 \%)$ \\
1 & $2(20 \%)$ \\
$>1$ & $1(10 \%)$ \\
Luminal surgery & $2(20 \%)$ \\
Anal surgery & $4(40 \%)$ \\
Drainage with setons & $3(30 \%)$ \\
Fistulotomy & $1(10 \%)$ \\
Change of biotherapy & $2(20 \%)$ \\
Hospitalization & $4(40 \%)$ \\
1 & $2(20 \%)$ \\
$>1$ & $2(20 \%)$ \\
Antibiotic therapy & $2(20 \%)$ \\
Steroids & $0(0 \%)$ \\
\hline
\end{tabular}

patients required one or more changes in the maintenance treatment. Finally, two patients received luminal surgeries: one ileocecal resection for stenosis and a new colostomy due to anastomotic leakage after stoma reversal surgery which was permitted by complete healing of fistula at 1 year. No neoplastic changes/transformation was observed. These adverse events were not considered to be related to the cell-based treatment, but rather to the classic and frequent progression of fistulizing perianal disease.

At 3 years, $70 \%$ of patients had achieved combined remission (Table 3). Five out of six patients (83\%) were in combined remission at both 1 and 3 years. One patient in combined remission at 1 year relapsed but did not require a change in therapy or surgical management. Two patients achieved delayed combined remission at 3 years. Finally, two patients were non-responders at one or 3 years and were considered to have failed (Fig. 1). One of the patients who was in combined remission at 1 year and 3 years discontinued maintenance treatment due to an improvement in luminal disease. The baseline and 3-year mean PDAI scores were similar, while they improved at 1 year (Table 3 ). The significant improvement in quality of life assessed by the SIBDQ score observed at 1 year was maintained at 3 years (Table 3 ).

MRI scans were analysed according to the MAGNIFICD score, proposed by Hindryckx et al. [10], by an experienced radiologist specializing in digestive disease at baseline, 1 year and 3 years after the injection. The calculation of the score is based on the following parameters: type of fistula (simple, complex), hyper-intensity of the primary tract on post-contrast T1-weighted images, dominant feature (fibrous, inflammatory or fluid), length and extension of the fistula and presence of an inflammatory mass/collection. The MAGNIFI-CD score ranges from 0 (inactive disease) to 25 (severe disease). An improvement in the mean MAGNIFI-CD MRI score was

Table 3 Study outcomes over time

\begin{tabular}{|c|c|c|c|}
\hline Study outcomes & Baseline & 1 year & 3 years \\
\hline Combined remission & & $6(60 \%)$ & $7(60 \%)$ \\
\hline Response $^{*}$ & & $2(20 \%)$ & $0(0 \%)$ \\
\hline No response & & $2(20 \%)$ & $3(30 \%)$ \\
\hline PDAl score $^{+}$ & $7.3 \pm 2.7$ & $3.4 \pm 4.3$ & $7.2 \pm 5.2$ \\
\hline SIBDQ score ${ }^{\ddagger}$ & $43.4 \pm 11.9$ & $47.0 \pm 11.4$ & $49.0 \pm 13.2$ \\
\hline MAGNIFI-CD score & Baseline & 1 year & 3 years \\
\hline \multicolumn{4}{|l|}{ All patients $(n=10)$} \\
\hline IRM total score & $17.8 \pm 4.9$ & $16.2 \pm 6.1$ & $14.7 \pm 5.7$ \\
\hline Change from baseline & $-1.6 \pm 3.1$ & $-3.1 \pm 3.3$ & \\
\hline \multicolumn{4}{|c|}{ Patients in remission at 3 years $(n=7)$} \\
\hline IRM total score & $16.8 \pm 5.9$ & $14.3 \pm 6.0$ & $11.5 \pm 4.3$ \\
\hline Change from baseline & $-2.5 \pm 2.4$ & $-5.3 \pm 1.8$ & \\
\hline \multicolumn{4}{|c|}{ Patients without response at 3 years $(n=3)$} \\
\hline IRM total score & $19.3 \pm 3.0$ & $19.0 \pm 5.8$ & $19.5 \pm 4.0$ \\
\hline Change from baseline & $0.3 \pm 3.9$ & $0.3 \pm 1.3$ & \\
\hline
\end{tabular}

Data represent frequency $n$ (\%) or mean and standard deviation

† Perianal Crohn's Disease Activity Index

‡ Short Inflammatory Bowel Disease Questionnaire

${ }^{*}$ Clinical improvement in suppuration but without reach combined remission outcome 

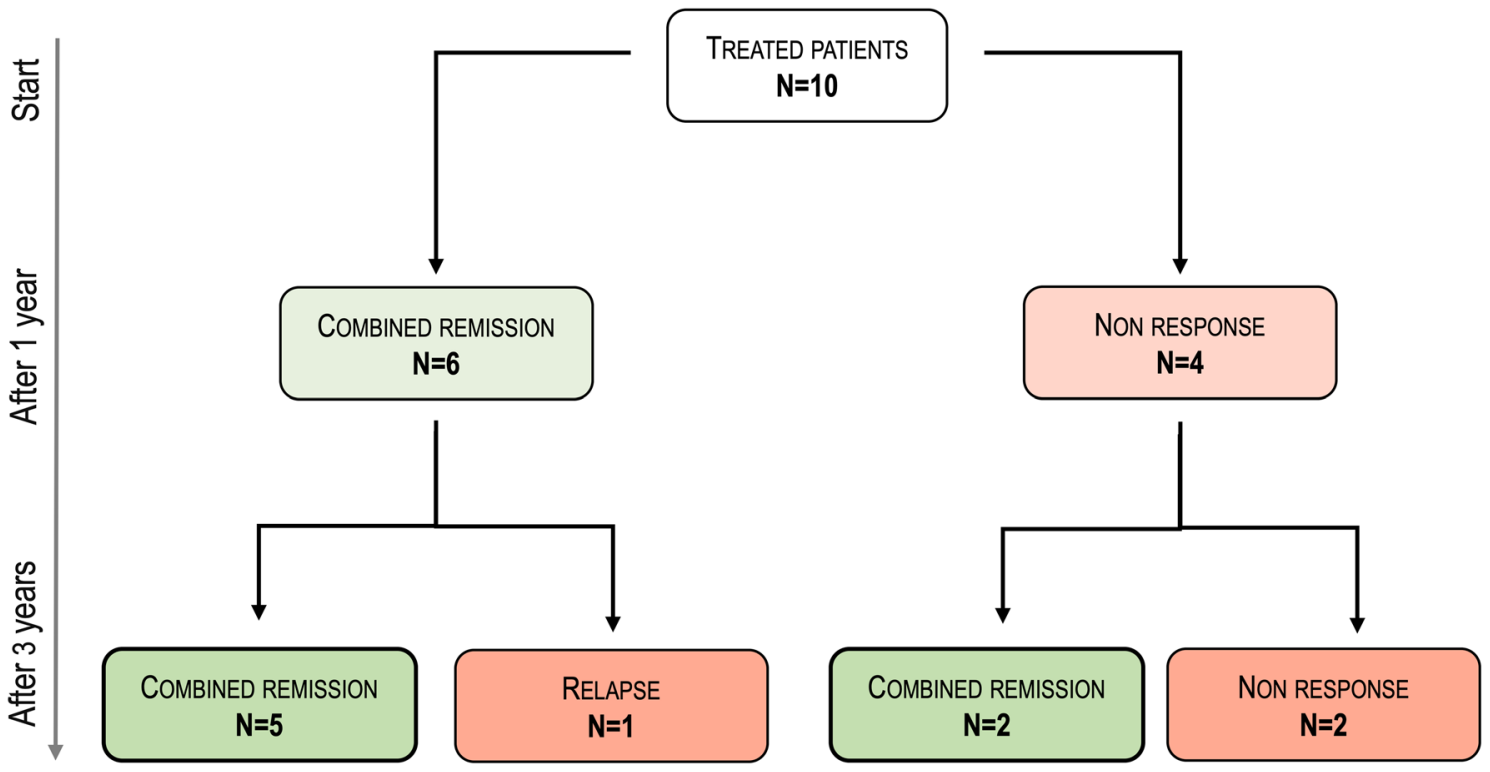

Fig. 1 Efficacy results at 1 year and 3 years

observed at 3 years compared to baseline (17.8 \pm 4.9 to $14.7 \pm 4.7$ ) (Table 3). The dominant feature of the fistula tract (fibrous, inflammatory or fluid) was the only parameter numerically improved. Finally, the number, length and extension of the fistulas did not change with treatment over time. In patients with combined remission at 3 years, the MAGNIFI-CD score improved individually in each patient and improved overall at 3 years compared to baseline (16.8 \pm 5.9 to $11.5 \pm 4.3$ ) (Table 2). In contrast, in patients who failed treatment and those with recurrence, the score was similar at baseline and 3 years $(19.3 \pm 3.0$ to $19.5 \pm 4.0)$ (Table 3).

\section{Discussion}

The injection of adipose tissue-derived products is emerging as a new therapeutic option. Various Preclinical models have documented the superiority of ADSVF over purified stem cells for tissue repair, lying on the heterogeneity of ADSVF that gathers various cell types displaying synergistic regenerative properties [6]. In addition, the local injection of both ADSVF and microfat is expected to provide complementary effects: ADSVF supports strong regenerative effects while microfat allows a volumizing effects that facilitates closure of fistulas [8]. We reported here that local injection of ADSVF and microfat did not cause any adverse effects over a 3-year follow-up period, providing evidence of a good long-term safety profile. The adverse events observed were considered to be expected as Crohn's disease progresses.

Importantly, this procedure led to combined remission for $70 \%$ of patients at 3 years. This high rate of efficacy provides the first evidence of a long-lasting healing effect of the innovative procedure, as $83 \%$ of patients maintained the combined remission observed at 1 year. In addition, our results also indicate a possible delayed effect of SVF and microfat. Indeed, two patients achieved combined remission only at 3 years. This hypothesis is supported by the absence of change in pharmacological treatment or surgery of the treated fistula in one patient. However, for the other patient who had a substantial treatment change and received surgical drainage with setons, it is difficult to specifically attribute the positive outcome to the study procedure. Of note, the level of remission at 3 years was not associated with a significant improvement in the PDAI score, whereas it was at 1 year. Consistently, in the ADMIRE study, success of perianal fistulas healing with expanded allogeneic MSCs did not impact the PDAI score at 24 and 52 weeks follow-up [4, 5].

Although the promise of ADSVF-based therapy has been documented in various pathologies, long-term efficacy is rarely reported. We previously reported data in favour of the long-term safety and efficacy of ADSVF injection in the hands of patients with systemic sclerosis [11]. In the field of Crohn's disease, long-term studies only concerned expanded MSC, mainly reported data from 1 year follow-up [12] or evaluated repeated cellbased therapy procedures. Ciccocioppo and colleagues reported a 4-year follow-up with a $37 \%$ probability of fistula relapse-free survival after multiple injections of bone marrow MSCs [13]. Guadalajara et al. also described a two-step injection procedure of ADSCs mixed with fibrin 
glue with $40 \%(2 / 5)$ of patients sustaining remission at 3 years [14]. A common point between these studies was the limited number of patients followed in the long term $[13,14]$.

In conclusion, we confirmed the safety profile of an innovative cell-based therapy approach combining ADSVF and autologous microfat injection in refractory complex perianal fistulas of Crohn's disease and provided efficacy data in long-term assessment. As it was a pilot protocol, our study was limited by its retrospective design, the small number of patients and the absence of a control group. Accordingly, a dedicated randomized placebo-controlled trial is currently conducted (NCT04010526) to assess the efficacy of ADSVF and microfat and define the place for this approach in the current therapeutic arsenal.

\section{Abbreviations}

ADICROHN: ADlpose-derived stromal vascular fraction with microfat for refractory perianal CROHN's fistulas;" ADSVF: Adipose-derived stromal vascular fraction; MRI: Magnetic resonance imaging; MSC: Mesenchymal stem cell; PDAI: Perianal Crohn's Disease Activity Index; SIBDQ: Short Inflammatory Bowel Disease Questionnaire.

\section{Acknowledgements}

The authors are grateful to the technical team of the APHM cell therapy unit who carried out the manufacturing of cell products; to the staff of the haematology laboratory of APHM (Pr Françoise Dignat-George) for support in quality control assays; to Dr Jerôme Soussan, who reviewed all patients' magnetic resonance imaging (MRI) examinations in a blinded fashion; to the anaesthesia and surgery team for their important contribution on the day of the surgical procedures; and to Dr Pierre-Charles Orsoni and Pr Dominique Casanova for sharing their expertise in the surgical aspects of treatment. We also acknowledge Professor Guy Magalon, who participated in the design of the trial and promoted innovative cell therapy within our university hospital. All authors have read and agreed to the final version of the manuscript, including the authorship list.

\section{Authors' contributions}

JCG, MS and FG took part in study concept and design. LG and FH took part in collection and acquisition of data. FH and CP (Caroline Prost) involved in analysis and interpretation of data. EJ participated in methodology and statistical analysis. LBB, CV, CP (Cécile Philandrianos), MA and ML involved in management of patients'surgical treatment; AD, MS and JCG involved in management of patient's medical treatment. JV took part in management of cell products' manufacturing; LG and FG involved in drafting of the manuscript. FS, JCG, MS and JM took part in critical revision of the manuscript for important intellectual content. FDG and JCG involved in study supervision. All authors read and approved the final manuscript.

\section{Funding}

This research was funded in part by the Assistance Publique Hôpitaux de Marseille.

\section{Availability of data and materials}

All data generated or analysed during this study are included in this published article.

\section{Declarations}

Ethics approval and consent to participate

The protocol was approved by the national ethics committee, and each patient gave written informed consent. The study was conducted according to the Declaration of Helsinki, as well as relevant international, national and local rules and regulations.

\section{Consent for publication}

Not applicable.

\section{Competing interests}

L Guillo declares consulting fees for AbbVie. JC Grimaud has served as a consultant for AbbVie, Takeda and Janssen and as a speaker for AbbVie, Takeda, Janssen and MSD. M Serrero declares lecture and consulting fees for AbbVie, Celltrion, Ferring, Janssen, MSD, Takeda and Tillotts. JM received honorarium for educational support from FIDIA, HORIBA and MACOPHARMA. The remaining authors declare no conflict of interest.

\section{Author details}

${ }^{1}$ Gastroenterology Department, Assistance Publique Hôpitaux de Marseille, University Hospital of Marseille Nord (AP-HM), Chemin des Bourrely, 13015 Marseille, France. ${ }^{2}$ Cell Therapy Department, INSERM CBT-1409, Assistance Publique Hôpitaux de Marseille, Aix-Marseille University, Marseille, France. ${ }^{3}$ Department of Radiology, Assistance Publique Hôpitaux de Marseille, Marseille, France. ${ }^{4}$ Statistical Department, Assistance Publique Hôpitaux de Marseille, Marseille, France. ${ }^{5}$ Plastic Surgery Department, Assistance Publique Hôpitaux de Marseille, Marseille, France. ${ }^{6}$ Digestive Surgery Department, Assistance Publique Hôpitaux de Marseille, Marseille, France. ${ }^{7}$ C2VN, INSERM UMR 1263, Faculté de Pharmacie de Marseille, Aix Marseille University, Marseille, France. ${ }^{8}$ Department of Anaesthesia and Intensive Care, Assistance Publique Hôpitaux de Marseille, Marseille, France. ${ }^{9}$ Centre d'Investigation Clinique 1409, Assistance Publique Hôpitaux de Marseille, Aix Marseille University, Marseille, France.

Received: 10 May 2021 Accepted: 20 January 2022

Published online: 09 February 2022

\section{References}

1. Eglinton TW, Barclay ML, Gearry RB, Frizelle FA. The spectrum of perianal Crohn's disease in a population-based cohort. Dis Colon Rectum. 2012:55:773-7.

2. Yassin NA, Askari A, Warusavitarne J, et al. Systematic review: the combined surgical and medical treatment of fistulising perianal Crohn's disease. Aliment Pharmacol Ther. 2014:40(7):741-9.

3. Molendijk I, Nuij VJAA, van der Meulen-de Jong AE, van der Woude CJ. Disappointing durable remission rates in complex Crohn's disease fistula. Inflamm Bowel Dis. 2014;20:2022-8.

4. Panés J, García-Olmo D, Assche GV, et al. Expanded allogeneic adiposederived mesenchymal stem cells (Cx601) for complex perianal fistulas in Crohn's disease: a phase 3 randomised, double-blind controlled trial. Lancet. 2016;388:1281-90.

5. Panés J, García-Olmo D, Assche GV, et al. Long-term efficacy and safety of stem cell therapy (Cx601) for complex perianal fistulas in patients with Crohn's disease. Gastroenterology. 2018;154:1334-1342.e4.

6. Bora P, Majumdar AS. Adipose tissue-derived stromal vascular fraction in regenerative medicine: a brief review on biology and translation. Stem Cell Res Ther. 2017;8:145.

7. Nguyen A, Guo J, Banyard DA, et al. Stromal vascular fraction: a regenerative reality? Part 1: current concepts and review of the literature. J Plast Reconstr Aesthet Surg. 2016;69:170-9.

8. Serrero M, Grimaud F, Philandrianos C, et al. Long-term safety and efficacy of local microinjection combining autologous microfat and adiposederived stromal vascular fraction for the treatment of refractory perianal fistula in Crohn's disease. Gastroenterology. 2019;156:2335-2337.e2.

9. Philandrianos C, Serrero M, Grimaud F, et al. First clinical case report of local microinjection of autologous fat and adipose-derived stromal vascular fraction for perianal fistula in Crohn's disease. Stem Cell Res Ther. 2018;9:4.

10. Hindryckx P, Jairath V, Zou G, et al. Development and validation of a magnetic resonance index for assessing fistulas in patients with Crohn's disease. Gastroenterology. 2019;157:1233-1244.e5. 
11. Daumas A, Magalon J, Jouve E, et al. Long-term follow-up after autologous adipose-derived stromal vascular fraction injection into fingers in systemic sclerosis patients. Curr Res Transl Med. 2017;65:40-3.

12. Ko JZ-H, Johnson S, Dave M. Efficacy and safety of mesenchymal stem/ stromal cell therapy for inflammatory bowel diseases: an up-to-date systematic review. Biomolecules. 2021;11:82.

13. Ciccocioppo R, Gallia A, Sgarella A, et al. Long-term follow-up of crohn disease fistulas after local injections of bone marrow-derived mesenchymal stem cells. Mayo Clin Proc. 2015:90:747-55.

14. Guadalajara H, Herreros D, De-La-Quintana P, et al. Long-term follow-up of patients undergoing adipose-derived adult stem cell administration to treat complex perianal fistulas. Int J Colorectal Dis. 2012;27:595-600.

\section{Publisher's Note}

Springer Nature remains neutral with regard to jurisdictional claims in published maps and institutional affiliations.

- fast, convenient online submission

- thorough peer review by experienced researchers in your field

- rapid publication on acceptance

- support for research data, including large and complex data types

- gold Open Access which fosters wider collaboration and increased citations

- maximum visibility for your research: over $100 \mathrm{M}$ website views per year

At BMC, research is always in progress.

Learn more biomedcentral.com/submissions 